\title{
Gold nanorod-encapsulated biodegradable polymeric matrix for combined photothermal and chemo-cancer therapy
}

This article was published in the following Dove Press journal: International Journal of Nanomedicine

\author{
Chun-Chiao Chuangl,* \\ Chih-Chi Chengl,* \\ Pei-Ying Chen' \\ Chieh Lo' \\ Yi-Ning Chen' \\ Min-Hsiung Shih ${ }^{2,3}$ \\ Chien-Wen Chang' \\ 'Department of Biomedical \\ Engineering and Environmental \\ Sciences, National Tsing Hua \\ University, Hsinchu 300 I3, Taiwan, \\ Republic of China; ${ }^{2}$ Research Center \\ of Applied Sciences (RCAS), Academia \\ Sinica, Taipei, II529, Taiwan, Republic \\ of China; ${ }^{3}$ Department of Photonics, \\ National Chiao Tung University \\ (NCTU), Hsinchu, 300 I0, Taiwan, \\ Republic of China \\ *These authors contributed equally \\ to this work
}

\begin{abstract}
Purpose: A biocompatible nanocomplex system co-encapsulated with gold nanorods (AuNRs) and doxorubicin (DOX) was investigated for its potentials on the combined photothermal- and chemotherapy.
\end{abstract}

Materials and methods: Hydrophobic AuNRs were synthesized by the hexadecyltrimethylammonium bromide (CTAB)-mediated seed growth method, and then, they received two-step surface modifications of polyethylene glycol (PEG) and dodecane. The AuNR/DOX/poly(lacticco-glycolic acid) (PLGA) nanocomplexes were prepared by emulsifying DOX, AuNR, and PLGA into aqueous polyvinyl alcohol solution by sonication. Human serum albumin (HSA) was used to coat the nanocomplexes to afford HSA/AuNR/DOX-PLGA (HADP). Size and surface potential of the HADP nanocomplexes were determined by using a Zetasizer. Cytotoxicity and cellular uptake of the HADP were analyzed by using MTT assay and flow cytometry, respectively. In vitro anticancer effects of the HADP were studied on various cancer cell lines. To assess the therapeutic efficacy, CT26 tumor-bearing mice were intravenously administered with HADP nanocomplexes and laser treatments, followed by monitoring of the tumor growth and body weight.

Results: Size and surface potential of the HADP nanocomplexes were $245.8 \mathrm{~nm}$ and $-8.6 \mathrm{mV}$, respectively. Strong photothermal effects were verified on the AuNR-loaded PLGA nanoparticles (NPs) in vitro. Rapid and repeated drug release from the HADP nanocomplexes was successfully achieved by near-infrared (NIR) irradiations. HSA significantly promoted cellular uptake of the HADP nanocomplexes to murine colon cancer cells as demonstrated by cell imaging and flow cytometric studies. By combining photothermal and chemotherapy, the HADP nanocomplexes exhibited strong synergistic anticancer effects in vitro and in vivo.

Conclusion: An NIR-triggered drug release system by encapsulating hydrophobic AuNR and DOX inside the PLGA NPs has been successfully prepared in this study. The HADP NPs show promising combined photothermal- and chemotherapeutic effects without inducing undesired side effects on a murine colon cancer animal model.

Keywords: gold nanomaterials, photothermal therapy, triggered drug release, albumin, biodegradable nanoparticles

\section{Introduction}

Clinical usages of conventional anticancer drugs still suffer from various drawbacks, such as causing side effects on normal tissues, insufficient drug accumulation in tumors, and development of drug-resistant cancer cells. ${ }^{1-3}$ Better patient compliance and therapeutic outcomes may be achieved by utilizing external stimulus-triggerable mechanism to deliver chemotherapeutics into tumors in spatial- and temporal-controlled manners. Light, $\mathrm{pH}$, redox, ultrasound, or magnetic fields are useful external stimulus 
on designing triggerable drug delivery systems. ${ }^{4-14}$ In the regard of light-responsive drug delivery system, various photothermal agents, such as surface plasmonic nanomaterials, have been adopted as the source of generating photohyperthermia effects upon receiving near-infrared (NIR) photons (700-900 nm) irradiations. ${ }^{15-20}$ It was confirmed that NIR photons could deeply penetrate into biological tissues due to their low absorption coefficients in water, lipids, and hemoglobin. ${ }^{21}$ These nanomaterials could effectively convert the absorbed NIR photons into heat. Thus, it is possible to achieve spatially accurate photothermal treatments on tumors while avoiding damage in the surrounded normal tissues. ${ }^{22-26}$ In addition to its direct anticancer effects, the photo-induced heat can increase sensitivity of cancer cells to chemotherapeutic agents by increasing membrane permeability and blood vessel dilation. ${ }^{27}$ These findings provide strong basis to combine photothermal therapy and chemotherapy for cancer treatments. ${ }^{1,16,28-30}$

Plasmonic gold nanomaterials (ie, gold nanosphere, gold nanorod [AuNR], gold nanoring, gold nanocage, and gold nanoshell) have shown great potentials on cancer photothermal therapy. Compared to other gold nanomaterials, AuNR is especially advantageous on its greater photothermal conversion efficiency and geometry-controlled photo activation window. ${ }^{31}$ AuNR could be utilized as a delivery carrier by loading drugs via covalent conjugation ${ }^{32}$ or noncovalent surface absorption. ${ }^{33}$ By either way, the surface-immobilized drugs could be later released in respond to an external stimulus. Meanwhile, under in vivo conditions, these surface-anchored drug loading designs may encounter various challenges on colloidal stability and significant drug leakage. We rationale that co-encapsulation of AuNR with drugs into biodegradable poly(lactic-co-glycolic acid) (PLGA) nanoparticles (NPs) should overcome these hurdles by stabilizing the encapsulated drugs in an isolated hydrophobic polymeric environment. Upon receiving NIR irradiation, the hyperthermia generated from AuNR could melt PLGA matrix for rapid drug release.

To maximize the delivery efficiency toward tumors, the short circulation half-life of injected NPs may be improved by conducting surface modifications to avoid rapid clearance from reticuloendothelial system (RES). Albumins are serum-derived proteins that show ideal characteristics for preparing long-circulating drug carriers. ${ }^{34-38}$ Abraxane (Celgene Corporation, Summit, NJ, USA), an albumin NP-based drug, is currently available as the first-line cancer therapeutic drug. Albumin is capable of binding to $60 \mathrm{kDa}$ glycoprotein (gp60) receptors expressed on vascular endothelial cells and then undergoes transcytosis into the interstitial area of tumor site. Once located in the tumor sites, albumins could bind to secreted protein acidic and rich in cysteine (SPARC), a cancer cell-overexpressed extracellular matrix glycoprotein, for subsequent uptake by cancer cells. ${ }^{39-44}$ In this study, we present a light-responsive triggered drug delivery system - human serum albumin (HSA)decorated PLGA NPs containing AuNR and doxorubicin (DOX) for cancer therapy (Scheme 1). It is anticipated that surface decoration of albumin would aid on the bioavailability and tumor targeting of drug delivery nanocarriers. The NPs were synthesized using a single emulsion method, ${ }^{45}$ followed by two-step surface depositions of bioreducible polyethylenimine (SPEI) and HSA via electrostatic interactions. The proposed nanocomplexes were characterized in terms of morphology, drug loading, surface modification size, and zeta potential. In vitro cellular uptake and anticancer effects of the HSA/AuNR/DOX-PLGA (HADP) nanocomplex were tested on cancer cell lines. To further evaluate the in vivo therapeutic efficacy, the murine colon cancer cells (CT26) of tumor-bearing mice (BALB/c) were treated by intravenous (i.v.) NP injections with NIR irradiation for hyperthermia activation to simultaneously induce the release of chemo drug and thermal ablation on tumors.

\section{Materials and methods Materials}

Hexadecyltrimethylammonium bromide (CTAB), ascorbic acid, triethylamine (TEA), and HSA were purchased from Sigma-Aldrich Co. (St Louis, MO, USA). 1-Dodecanethiol was purchased from Alfa Aesar (Ward Hill, MA, USA). Silver nitrate $\left(\mathrm{AgNO}_{3}\right)$ and hydrogen tetrachloroaurate (III) tetrahydrate $\left(\mathrm{HAuCl} 4 \cdot 4 \mathrm{H}_{2} \mathrm{O}\right)$ and trisodium citrate were purchased from Showa (Tokyo, Japan). PLGA (molecular weight $[M W]=40,000)$ was purchased from Green Square (Taipei, Taiwan, Republic of China). Polyvinyl alcohol (PVA) (MW=16,000) was purchased from Acros. Sodium tetrahydridoborate $\left(\mathrm{NaBH}_{4}\right)$ was purchased from Fluka. DOX was purchased from Seedchem. Dithiothreitol, MTT, and ampicillin were purchased from MDBio, Inc. (Taipei, Taiwan, Republic of China). Ethanol was purchased from Echo. Tetrahydrofuran (THF) was purchased from Tedia. Chloroform $\left(\mathrm{CHCl}_{3}\right)$ was purchased from J.T. Baker. DMEM and Dulbecco's phosphate-buffered saline (DPBS) were purchased from Thermo Fisher Scientific (Waltham, MA, USA). Penicillin-streptomycin (P/S) and FBS were purchased from HyClone (Logan, UT, USA). 


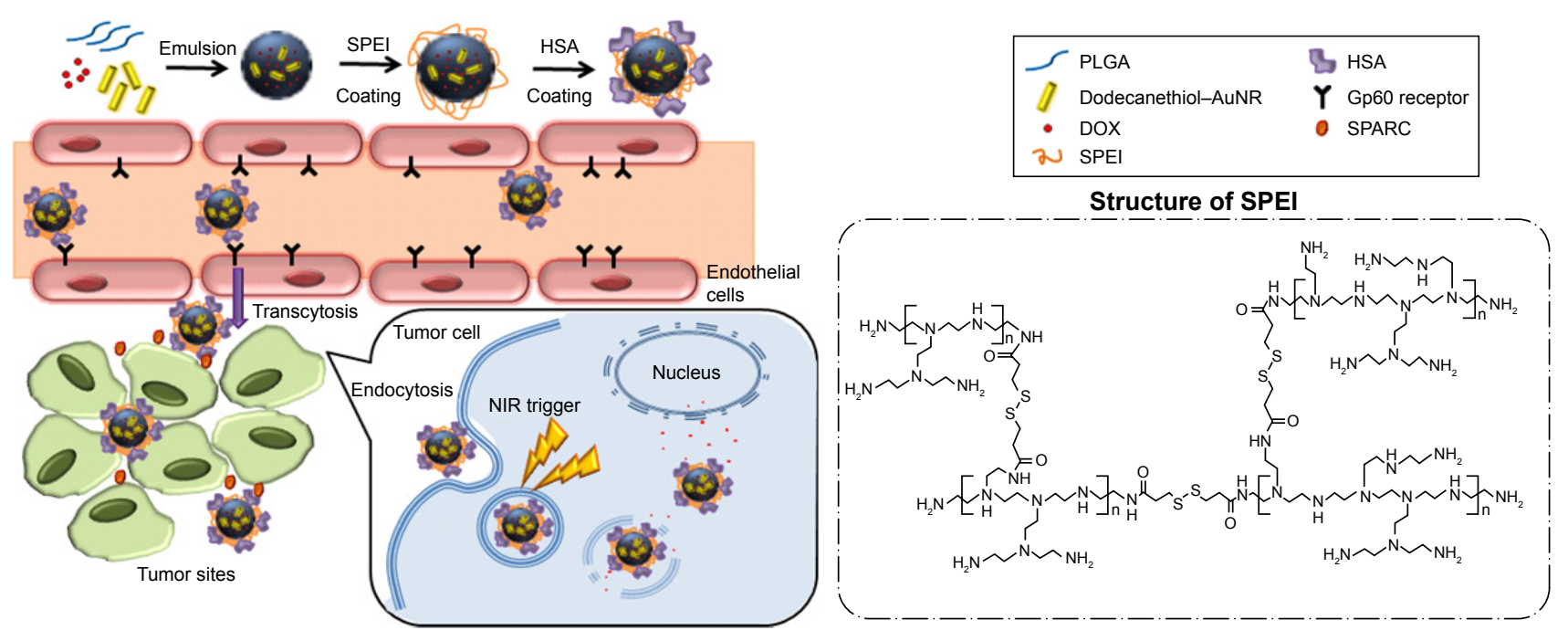

Scheme I Schematic illustration of the working mechanisms of combined photothermal therapy and chemotherapy by HADP.

Abbreviations: AuNR, gold nanorod; DOX, doxorubicin; HADP, HSA/AuNR/DOX-PLGA; HSA, human serum albumin; NIR, near infrared; PLGA, poly(lactic-co-glycolic acid); SPARC, secreted protein acidic and rich in cysteine; SPEI, bioreducible polyethylenimine.

\section{AuNRs' synthesis and surface modification}

AuNRs were synthesized using a modified seed-mediated growth method as previously reported. ${ }^{46-48}$ To synthesize the seed solution, $\mathrm{CTAB}$ aqueous solution $(0.1 \mathrm{M}, 15 \mathrm{~mL})$ was mixed with $\mathrm{HAuCl}_{4}(0.01 \mathrm{M}, 0.5 \mathrm{~mL})$ and then $\mathrm{NaBH}_{4}$ $(0.2 \mathrm{mM}, 120 \mathrm{~mL})$ was added with vigorous stirring. Next, CTAB (0.1 M, $42.75 \mathrm{~mL})$ was mixed with $\mathrm{HAuCl}_{4}(0.01$ $\mathrm{M}, 1.8 \mathrm{~mL})$ and $\mathrm{AgNO}_{3}(0.01 \mathrm{M}, 0.27 \mathrm{~mL})$. Ascorbic acid $(0.1 \mathrm{M}, 0.288 \mathrm{~mL})$ was added to the solution as a reducing agent. Seed solution $(1.44 \mathrm{~mL})$ was added to the solution and then reacted for 3 hours to obtain CTAB-coated AuNRs. To synthesize hydrophobic AuNR, a two-step ligand exchange method was utilized in this study. Polyethylene glycol (PEG)-thiol solution in water $(0.2 \mathrm{mM}, 12 \mathrm{~mL})$ was mixed with the synthesized AuNR and sonicated for 3 hours. The PEG-AuNR solution was centrifuged in deionized (DI) $\mathrm{H}_{2} \mathrm{O}$ at 15,000 rpm for 20 minutes, and the supernatant was removed. The PEG-AuNRs were resuspended in THF. Next, $0.145 \mathrm{~mL}$ of ethanolic dodecanethiol $(1 \mathrm{mg} / \mathrm{mL})$ was added to the PEG-AuNR solution and sonicated at $40^{\circ} \mathrm{C}$ for 3 hours. The dodecanethiol-AuNR solution was left overnight and centrifuged in $\mathrm{DI} \mathrm{H}_{2} \mathrm{O}$ at 15,000 rpm for 20 minutes, and the supernatant was discarded. The dodecane-AuNRs were re-dispersed in chloroform. ${ }^{49}$

\section{Preparation of AuNR/DOX/PLGA (ADP) NPs}

A total of $10 \mathrm{mg}$ of DOX was dissolved in $1 \mathrm{~mL}$ of dimethyl sulfoxide (DMSO) and $10 \mu \mathrm{L}$ of TEA. In all, $25 \mathrm{mg}$ of PLGA
(MW: 40,000) and dodecanethiol-AuNRs (OD=16.7 for low AuNR loading [L] and 100 for high AuNR loading [H]) were dissolved in $0.6 \mathrm{~mL}$ of chloroform and mixed with $0.25 \mathrm{~mL}$ of DOX solution. In all, $3 \mathrm{~mL}$ of $1 \%$ PVA solution was added into the oil phase and then sonicated for 1.5 minutes. ${ }^{50-52} \mathrm{Next}$, the organic solvent was removed by evaporating in a hood overnight. Finally, the ADP NPs were centrifuged in $\mathrm{DI}_{2} \mathrm{O}$ at $7,500 \mathrm{~g} / 15$ minutes for three times to remove unloaded drugs.

\section{HSA modification and characterization}

To have HSA modification on the surface of ADP NPs, a twostep procedure was performed. ADP NPs' aqueous dispersion $(10 \mathrm{mg} / \mathrm{mL}, 1 \mathrm{~mL})$ was dropwise added into the SPEI solution $(10 \mathrm{mg} / \mathrm{mL}, 1 \mathrm{~mL})$ and vortexed for 1 minute. SPEI was synthesized by crosslinking polyethylenimine (PEI; MW $800 \mathrm{Da}$ ) with $3,3^{\prime}$-dithiodipropanic acid as previously described. ${ }^{53}$ The structure of SPEI is shown in Scheme 1. SPEI-ADP NPs were centrifuged in $\mathrm{DI}_{2} \mathrm{O}$ at 7,000 g/15 minutes for three times to remove free SPEI. Then, SPEI-ADP NP solution $(2.5 \mathrm{mg} / \mathrm{mL}, 1 \mathrm{~mL})$ was dropwise added into the HSA solution $(2.5 \mathrm{mg} / \mathrm{mL}, 1 \mathrm{~mL})$ and vortexed for 1 minute. HADP nanocomplexes were obtained by centrifuging in DI $\mathrm{H}_{2} \mathrm{O}$ at $3,000 \mathrm{~g} / 20$ minutes for three times to remove free HSA.

\section{Characterizations and calculation of drug-loading content}

Particle size, polydispersity index (PDI), and surface charge were determined using the dynamic light scattering (DLS) method. Samples were appropriately diluted in distilled 
water. Transmission electron microscopy (TEM; JEM1200EX II; JEOL, Tokyo, Japan) was used to characterize the morphology of NPs. The amount of DOX loaded in the NPs was determined by fluorescence spectrophotometry. In all, $3 \mathrm{mg}$ of freeze-dried NPs was dissolved in $0.4 \mathrm{~mL}$ DMSO and incubated at $37^{\circ} \mathrm{C}$ overnight. Drug concentration was determined by measuring the optical absorption at $595 \mathrm{~nm}$, where no optical interference was detected from the PLGA matrix. Drug loading efficiency (LE) and encapsulation efficiency (EE) were calculated using the following formulas:

$$
\begin{aligned}
& \mathrm{LE}=\frac{\text { The weight of DOX in nanoparticles }}{\text { The weight of nanoparticles }} \times 100 \% \\
& \mathrm{EE}=\frac{\text { The weight of DOX in nanoparticles }}{\text { The total weight of feeding DOX }} \times 100 \%
\end{aligned}
$$

\section{Photothermal effects of HADP}

HADP (2.0 mg) with or without AuNR was dispersed in $0.2 \mathrm{~mL}$ deionized water. NIR laser probe $\left(808 \mathrm{~nm}, 1.5 \mathrm{~W} / \mathrm{cm}^{2}\right)$ was used for light irradiation while the temperature changes of the samples were recorded using a thermal camera.

\section{Photothermal effects on triggered DOX release}

Photothermal-mediated drug release of the HADP was studied at $37^{\circ} \mathrm{C}$ using a temperature-controlled water bath. HADP $(2.0 \mathrm{mg})$ with or without AuNR was dispersed in $0.2 \mathrm{~mL}$ PBS (10 mM, pH 7.4) containing 0.1\% Tween 80 in $1.5 \mathrm{~mL}$ tubes. ${ }^{45}$ At predesignated time intervals, the samples were irradiated with NIR laser $(808 \mathrm{~nm}, 1.5)$ for 4 minutes. The solution was centrifuged at $7,500 \times g$ for 15 minutes, and supernatants were analyzed for DOX amounts using a fluorescence plate reader.

\section{Cell cultures}

Murine colon cancer cell line (CT26) and human breast cancer cell line (MCF7) used in this study were originally obtained from American Type Culture Collection (ATCC). These cells were cultured in DMEM and supplemented with $10 \% \mathrm{FBS}$ at $37^{\circ} \mathrm{C}$ in a humidified incubator containing $5 \% \mathrm{CO}_{2}$.

\section{Cellular uptake of HADP NPs by human cancer cells}

CT26 cells were seeded in 24-well plates at the density of $8 \times 10^{4}$ cells/well in $0.5 \mathrm{~mL} 10 \% \mathrm{FBS} / \mathrm{DMEM}$. The cells were incubated with free DOX, ADP, and HADP (DOX concentration $10 \mu \mathrm{M}$ ) for 1 hour. After incubation, the cells were washed with PBS twice. After trypsin treatment, the cells were fixed with $400 \mu \mathrm{L}$ of $0.25 \%$ paraformaldehyde (PFA). Subsequently, the cells were analyzed using a flow cytometer (BD FACSCanto; BD Biosciences, San Jose, CA, USA) using CFlow Plus software. To image the cellular uptake, drug-containing NPs were incubated with the cells for 1 hour, followed by PBS washing twice to remove free NPs. The cells were fixed with $200 \mu \mathrm{L} 4 \%$ PFA. 4',6Diamidino-2-phenylindole (DAPI) was used to stain the cell nucleus. Images of cells were acquired using a fluorescence microscope (Carl Zeiss Meditec AG, Jena, Germany).

\section{In vitro cytotoxicity assays}

MCF7, MCF7/multidrug resistance (MDR), or CT26 cells $\left(5 \times 10^{4}\right.$ cells/well) were seeded in 24 -well plates with $0.5 \mathrm{~mL}$ $10 \%$ FBS DMEM. The cells were incubated with free DOX (10 or $15 \mu \mathrm{M}$ ) or HSA-DOX/PLGA (HDP) NPs, HSAAuNR/PLGA (HAP) NPs, and HADP (DOX concentration $10 \mu \mathrm{M}$ ) for 4 hours. Then, the cells were deployed to $1.5 \times 10^{6}$ cells $/ \mathrm{mL}$ and transferred into $1.5 \mathrm{~mL}$ tube to receive NIR irradiation for 5 minutes. After light treatment, the cells were incubated in 96-well plates for another 24 hours, and the cell viability was determined by MTT assay. For the MTT assay, the MTT reagent was diluted to $0.5 \mathrm{mg} / \mathrm{mL}$ and then added into the 96 wells for 4 hours at $37^{\circ} \mathrm{C}$. In the end, the supernatant was discarded. Later, $100 \mu \mathrm{L}$ of DMSO was added into each well and the plates were shaken for $\sim 1$ minute gently. Cell viability was determined by measuring the absorbance at the wavelength of $570 \mathrm{~nm}$ using a plate reader.

\section{In vivo photothermal effects}

The animals were handled in accordance to the animal use protocol approved by the Institutional Animal Care and Use Committee (IACUC; approval number: IACUC-10461) of the National Tsing Hua University, Hsinchu, Taiwan, Republic of China. Male BALB/c mice (6-8 weeks old and weighted 25-30 g) were purchased from the National Laboratory Animal Center in Taiwan, Republic of China. To set up the tumor model, CT26 cells $\left(2 \times 10^{6}\right.$ cells $/ 0.1 \mathrm{~mL}$ of PBS $)$ were subcutaneously inoculated into the right hind limb of the mice. The animals were chosen for in vivo studies when their tumor sizes reached $75 \mathrm{~mm}^{3}$. PBS, HAP, and HADP were injected via tail vein into tumor-bearing mice at doses equivalent to $15 \mathrm{mg} / \mathrm{kg}$ of DOX. Twenty-four hours after injection, the mice were irradiated at $808 \mathrm{~nm}\left(1.0 \mathrm{~W} / \mathrm{cm}^{2}\right)$ for 5 minutes. The temperature was recorded using a Mini Thermal imager (Avio NEC Thermo Shot F30W). 


\section{In vivo therapeutic efficacy of HADP with laser treatment}

The treatments were started when the CT26 tumor volumes reached $75 \mathrm{~mm}^{3}$. PBS, DOX, HDP, HAP, and HADP were injected via tail vein into tumor-bearing mice at doses equivalent to $15 \mathrm{mg} / \mathrm{kg}$ of DOX. In all, 24 and 48 hours after injection, laser irradiations were performed. Tumor size and body weight were measured every day for the duration of the experiment. The tumor size was calculated using the following equation:

\section{Tumor volume $=0.5 \times A \times B^{2}$}

where $A$ and $B$ represent the largest and smallest tumor diameters, respectively.

\section{Statistics}

Results of this study are presented as the mean and SD of at least three independent measurements. All statistical evaluations were carried out with unpaired two-tailed Student's $t$-test. $P$-value of less than 0.05 was considered as significant $(* P<0.05, * * P<0.01$, and $* * * P<0.001)$.

\section{Results and discussion \\ Preparation and characterizations of hydrophobic AuNRs}

AuNRs were synthesized using a seed-mediated growth method as previously described. ${ }^{54}$ Averaged length and width of the as-synthesized CTAB-AuNRs were approximately 40 and $10 \mathrm{~nm}$, respectively (Figure 1A). The CTAB-AuNRs were hydrophilic and incompatible with the hydrophobic
A

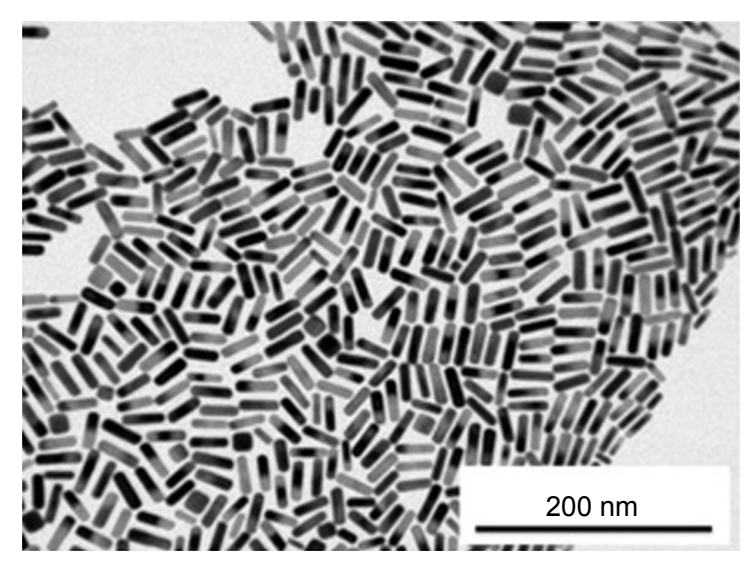

B

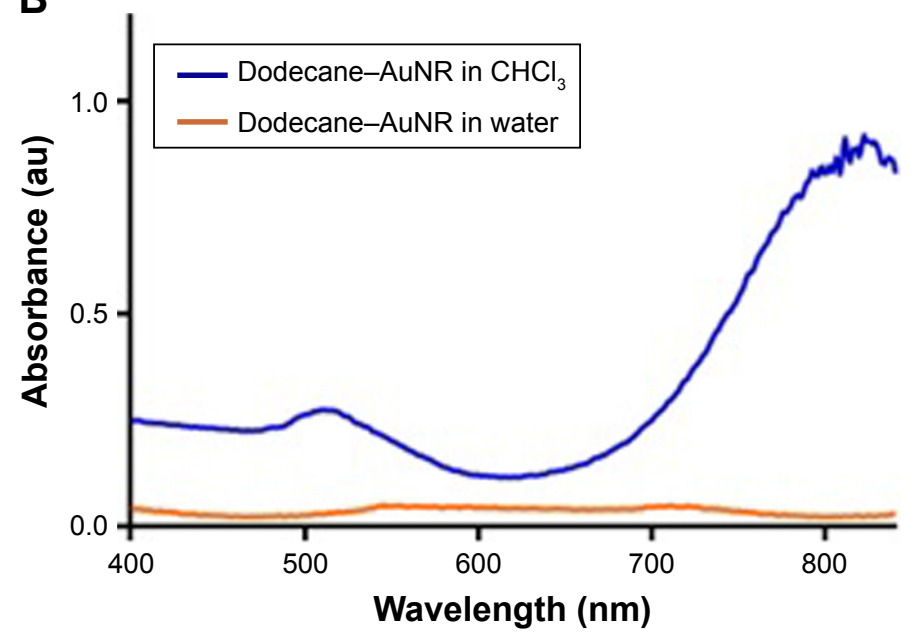

C

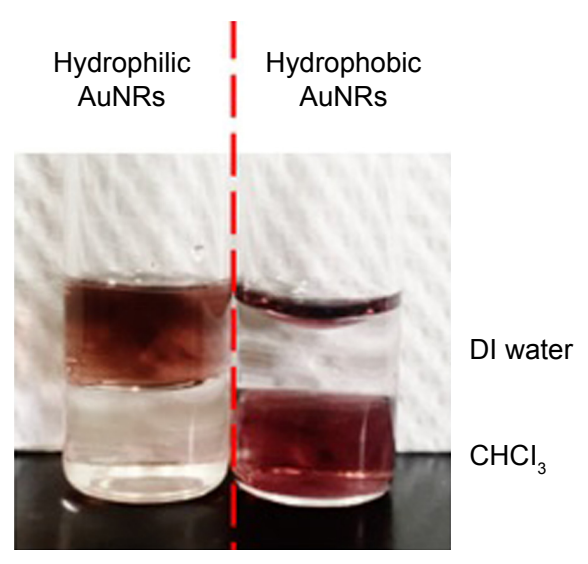

D

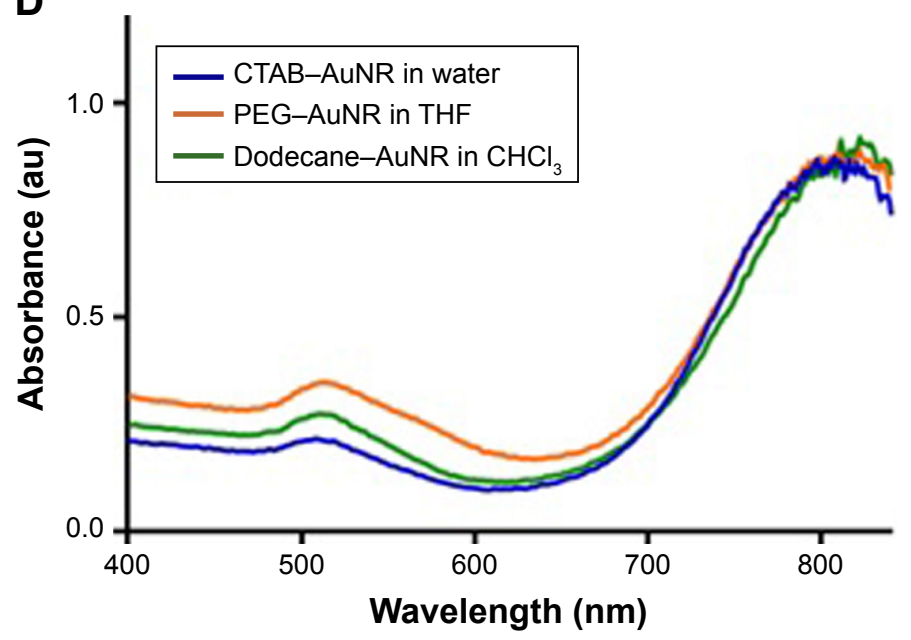

Figure I (A) TEM image of the as-prepared CTAB-AuNR. (B) UV-Vis spectrum of dodecane-AuNR in water and $\mathrm{CHCl}_{3}$. (C) Photograph showing the dispersion of different surface-modified AuNRs in the two phases. (D) UV-Vis spectrum of the different surface-modified AuNRs in various dispersed phases.

Abbreviations: au, atomic unit; AuNR, gold nanorod; CTAB, hexadecyltrimethylammonium bromide; DI, deionized; PEG, polyethylene glycol; TEM, transmission electron microscopy; THF, tetrahydrofuran; UV-Vis, ultraviolet-visible. 
Table I Characterizations of size/surface potential and drug encapsulation of the PLGA NPs produced by the single emulsion method

\begin{tabular}{|l|l|l|l|l|l|}
\hline & Size (d.nm) & Zeta $(\mathbf{m V})$ & PDI & LE (\%) & EE (\%) \\
\hline DOX/PLGA NPs & $204.7 \pm 2.9$ & $-9.99 \pm 0.5$ & 0.112 & 3.3 & 33.4 \\
\hline AuNR(L)/DOX/PLGA NPs & $216.7 \pm 3.9$ & $-10.4 \pm 0.7$ & 0.102 & 3.0 & 30.4 \\
\hline AuNR(H)/DOX/PLGA NPs & $217.4 \pm 3.1$ & $-11.3 \pm 0.1$ & 0.099 & 2.3 & 23.0 \\
\hline
\end{tabular}

Note: Data represent the mean $\pm S E ; n=3$.

Abbreviations: AuNR, gold nanorod; DOX, doxorubicin; EE, encapsulation efficiency; H, high AuNR loading; L, low AuNR loading; LE, loading efficiency; NP, nanoparticle; PDI, polydispersity index; PLGA, poly(lactic-co-glycolic acid); SE, standard error.

nature of PLGA NPs. To encapsulate AuNRs into the hydrophobic core of PLGA NPs, CTAB-AuNRs were modified by two-step ligand exchange reactions to obtain hydrophobic AuNRs. In the first step, CTAB-AuNRs were converted to PEG-AuNRs. PEG-thiol was conjugated to the AuNRs via efficient thiol-gold conjugation, and the resultant PEGAuNRs was well dispersed in water or THF. PEG-AuNRs were further converted to dodecane-AuNRs by reacting dodecanethiol with PEG-AuNRs under sonication at $40^{\circ} \mathrm{C}$ for 3 hours. Figure 1B shows that dodecane-AuNRs had good dispersibility in chloroform and the plasma resonance peaks were maintained at the NIR region (700 900 nm). In contrast, no optical absorption was observed from the precipitated dodecane-AuNRs in water. A simple extraction experiment (Figure 1C) confirmed the anticipated partitions of hydrophilic CTAB-AuNRs and hydrophobic dodecane-AuNRs in aqueous and organic phases, respectively. In addition, the results (Figure 1D) indicate that surface replacement of CTAB by PEG or dodecanethiol did not affect the optical properties of AuNRs. Taken together, hydrophobic AuNRs were successfully synthesized after two-step surface modifications.

\section{Preparation and characterizations of ADP NPs}

ADP NPs were prepared using a single emulsion method. The oil-in-water $(\mathrm{O} / \mathrm{W})$ emulsion process allows formation of the NPs encapsulated with hydrophobic cargos. The size of the NPs encapsulated with DOX and AuNR was $\sim 215 \mathrm{~nm}$ in diameter as measured using a ZetaSizer. Low PDI $(\sim 0.1)$ suggests that the NPs were prepared with narrow size distribution, and the zeta potential value was approximately $-10 \mathrm{mV}$ (Table 1). Encapsulating efficiency of DOX in the NPs was $~ 33 \%$ in the absence of AuNR and decreased when co-encapsulating with AuNR.

\section{Preparation and characterizations of HADP NPs}

The as-prepared PLGA NPs exhibited negative surface charge. SPEI, a bioreducible cationic polymer, was chosen as the interfacial layer for deposition of negatively charged HSA onto the PLGA NPs. SPEI has been used for effective non-viral gene delivery because of its excellent protonsponge effect and low cytotoxicity. We have previously shown that SPEI greatly promotes the cellular uptake of metal NPs ${ }^{55} \mathrm{~A}$ two-step procedure was conducted to deposit HSA on the surface of PLGA NPs. First, the PLGA NPs were coated with SPEI via electrostatic interactions to afford a positively charged surface. Increase in particle size was observed, and the zeta potential value turned from negative to positive values as expected (Table 2). Next, HSA was deposited onto the SPEI/PLGA NPs to obtain HSA/SPEI/ PLGA NPs as evident from surface charge reversal of the NPs. Taken together, the results suggest that the HSA/SPEI/ PLGA NPs were successfully prepared via the layer-by-layer process. TEM imaging results show that numerous AuNRs were successfully encapsulated in a PLGA NP (Figure 2A). Furthermore, the colloidal stability of HADP NPs in water or medium was examined (Figure 2B). No significant size increase or aggregation of NPs was observed in the presence of serum proteins within 24 hours, suggesting that HADP NPs may be further used in vivo.

\section{Photothermal effects of HADP}

HADP NPs were anticipated to convert NIR photons to heat through the mechanism of surface plasma resonance. The effects of NIR irradiation $\left(808 \mathrm{~nm}, 1.5 \mathrm{~W} / \mathrm{cm}^{2}\right)$ on the temperature of NPs solutions was studied using a thermal

Table 2 Effects of surface modifications on size/surface potential of the ADP NPs

\begin{tabular}{|l|l|l|l|}
\hline & Size $\mathbf{( d \cdot n m )}$ & Zeta $(\mathbf{m V})$ & PDI \\
\hline ADP NPs & $216.9 \pm 6.8$ & $-13.2 \pm 0.7$ & 0.103 \\
\hline SPEI/ADP NPs & $241.2 \pm 4.5$ & $32.9 \pm 0.2$ & 0.121 \\
\hline HSA-ADP NPs & $245.8 \pm 7.8$ & $-8.57 \pm 0.6$ & 0.111 \\
\hline
\end{tabular}

Note: Data represent the mean $\pm S E ; n=3$

Abbreviations: ADP, AuNR/DOX/PLGA; AuNR, gold nanorod; DOX, doxorubicin; HSA, human serum albumin; NIR, near infrared; NP, nanoparticle; PDI, polydispersity index; PLGA, poly(lactic-co-glycolic acid); SE, standard error; SPEI, surface depositions of bio-reducible polyethylenimine. 
A
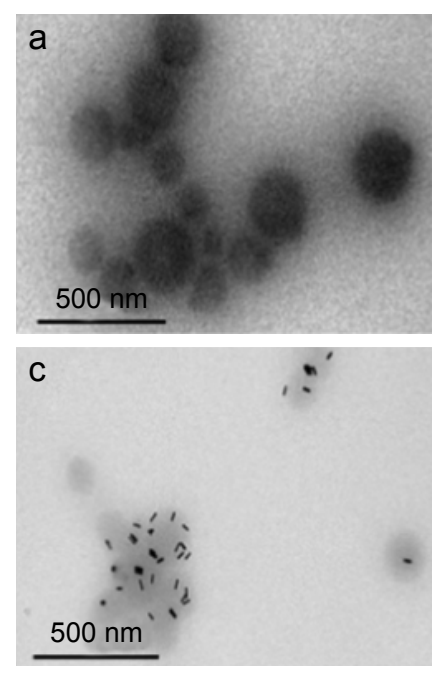
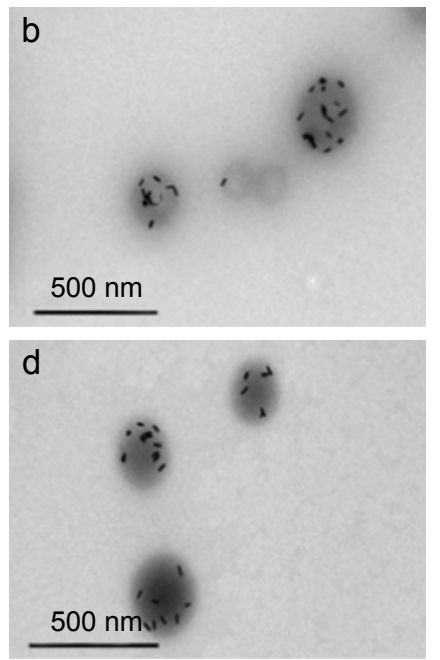

B

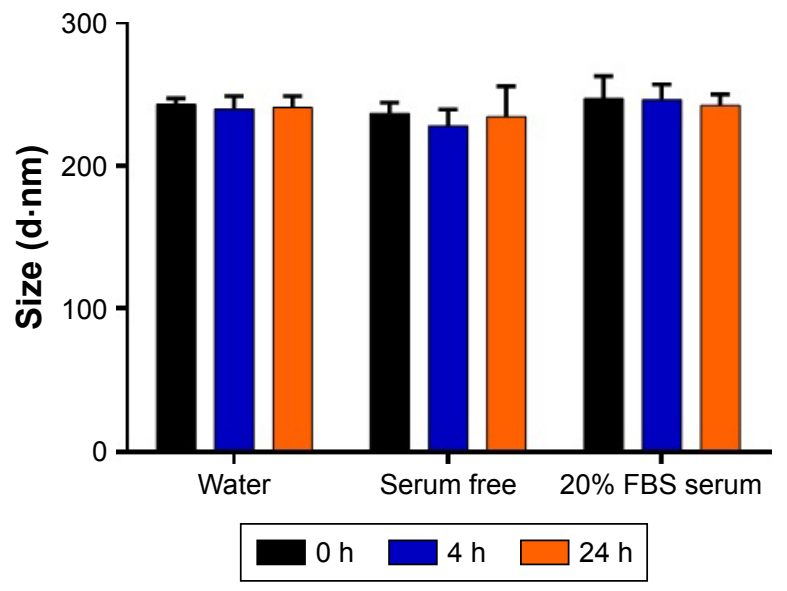

Figure 2 (A) TEM images of (a) PLGA NPs, (b) ADP NPs, (c) SPEI/ADP NPs, and (d) HSA/SPEI/ADP NPs. (B) Colloidal stability of the HADP in various conditions (water, serum-free medium, and $20 \%$ FBS serum-containing medium) for 0,4 , and 24 hours.

Note: Data represent the mean $\pm S E ; n=3$.

Abbreviations: ADP, AuNR/DOX/PLGA; AuNR, gold nanorod; DOX, doxorubicin; HADP, HSA/AuNR/DOX-PLGA; HSA, human serum albumin; NIR, near infrared; NP, nanoparticle; PLGA, poly(lactic-co-glycolic acid); SE, standard error; SPEl, surface depositions of bio-reducible polyethylenimine; TEM, transmission electron microscopy.

camera. After the NP solution was irradiated by NIR laser for continuous 5 minutes, temperature of the HADP NP solution increased remarkably compared to that of the HDP NP solution (Figure 3A). As expected, a higher extent of temperature increase was recorded from the NPs containing a higher amount of AuNRs. Specifically, solution temperature of the NPs containing high AuNR amounts increased linearly from $30^{\circ} \mathrm{C}$ to $67^{\circ} \mathrm{C}$ upon NIR irradiation. Repeated photothermal responses were also achieved from the HADP NPs (Figure 3B).

\section{Photothermal effects on triggered DOX release}

In this study, PLGA polymer (MW: 40,000) with glass transition temperature $\left(\mathrm{T}_{\mathrm{g}}\right)$ of $48^{\circ} \mathrm{C}-52^{\circ} \mathrm{C}$ was used to prepare the NPs. It was anticipated that, upon NIR irradiation, the generated heat would increase the fluidity of PLGA matrix to achieve rapid drug release. To confirm whether DOX could release from NPs, the HADP NP solution was irradiated by NIR laser $\left(808 \mathrm{~nm}, 1.5 \mathrm{~W} / \mathrm{cm}^{2}\right)$ and the amounts of DOX release were measured using a

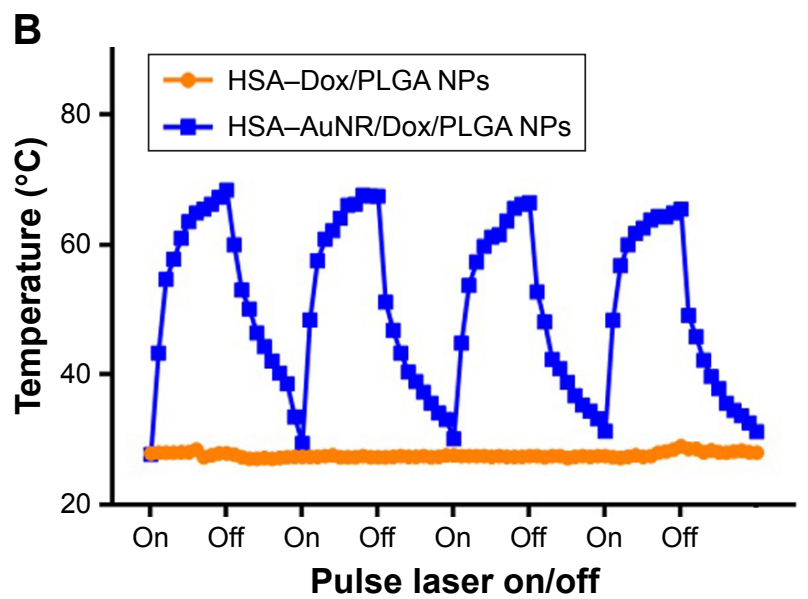

Figure 3 (A) Thermal images of HSA-coated NPs after receiving NIR irradiation for 5 minutes. (B) NIR laser $\left(808 \mathrm{~nm}, 1.5 \mathrm{~W} / \mathrm{cm}^{2}\right)$ induced temperature changes in the HDP NPs (orange plot) and HADP NPs (blue plot). Repeated temperature raise was observed from HADP NPs after each light irradiation.

Note: Data represent the mean $\pm S E ; n=3$.

Abbreviations: AuNR, gold nanorod; DOX, doxorubicin; HADP, HSA/AuNR/DOX-PLGA; HDP, HSA-DOX/PLGA; HSA, human serum albumin; NIR, near infrared; NP, nanoparticle; PLGA, poly(lactic-co-glycolic acid); SE, standard error. 
fluorescence plate reader. After three cycles of NIR light irradiation ( $3 \times 3$ minutes), the accumulative DOX release (Figure 4) achieved $~ 59 \%$, which was much higher than the accumulative DOX release from the HADP NP solutions without receiving NIR irradiations. The results indicate that multiple light-triggered enhanced DOX release can be achieved successfully.

\section{In vitro cellular uptake}

Cellular uptake of the HADP NPs was studied on the CT26 cell line using fluorescence microscope and flow cytometry. As shown in Figure 5A, more intracellular DOX accumulation (red fluorescence) in the cancer cells of the HADP group was observed than that in the CT26 cell line of free DOX or ADP group. Enhancement effects of HSA on cancer cellular uptake of the NPs were blocked by adding free HSA. Similarly, flow cytometric analysis shows that average DOX fluorescence intensity of the HADP group was 2.4-fold higher than that of the HSA blocking group on CT26 cell lines (Figure 5B and C), which was consistent to the fluorescent microscopic observations. The observed phenomenon suggests that enhanced cellular uptake of HADP was attained via the interactions between HSA and its receptor on cancer cells. ${ }^{34}$

\section{In vitro anticancer effects}

To verify the anticancer effect of HADP NPs after laser irradiation, the combined photothermal therapy and chemotherapy effect of HADP was evaluated on the CT26 cells (Figure 6A). While the HDP NPs are essentially nontoxic to the cellular host in the absence of external laser treatment,

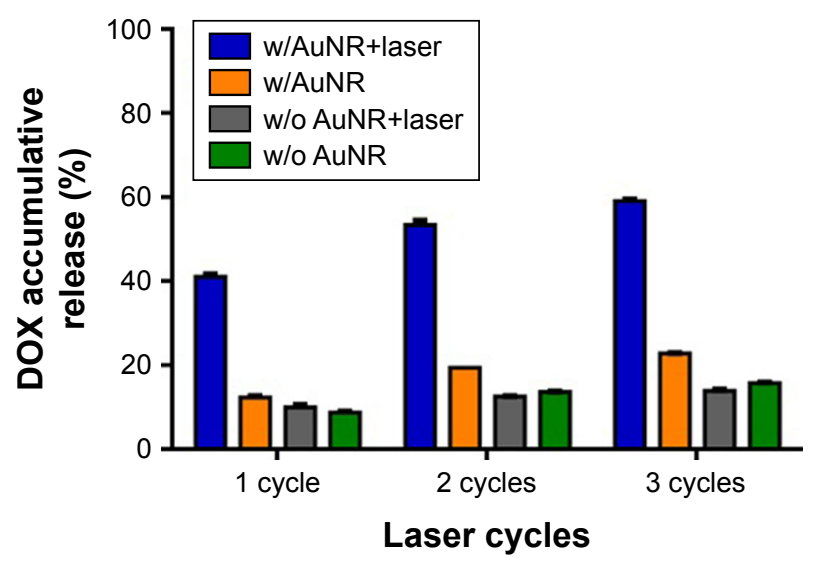

Figure 4 NIR laser-triggered drug release of the drug-containing PLGA NPs. Notes: Accumulative DOX release was calculated after each cycle of laser irradiation ( $1.5 \mathrm{~W} / \mathrm{cm}^{2}, 3$ minutes). Data represent the mean $\pm S E ; n=3$.

Abbreviations: AuNR, gold nanorod; DOX, doxorubicin; NIR, near infrared; NP, nanoparticle; PLGA, poly(lactic-co-glycolic acid); SE, standard error; w/, with; w/o, without. the survival rate of the HADP group receiving photothermal activation by laser illumination was significantly reduced to $31.6 \%$ at $1.3 \mathrm{~W} / \mathrm{cm}^{2}$ and $10.9 \%$ at $1.5 \mathrm{~W} / \mathrm{cm}^{2}$. In addition, high cell viability was maintained after treating with various NPs (HDP, HAP, or HADP) without further laser irradiation. Notably, the cell viability of the HADP group (10.9\%) with $1.5 \mathrm{~W} / \mathrm{cm}^{2}$ laser irradiation was lower than that of the free DOX group (30.9\%), which means that HADP NPs display the higher killing effect.

Development of MDR to chemotherapy is still of big challenge for clinical cancer treatments. P-glycoprotein (P-gp) is one type of membrane transporters that could rapidly efflux chemo drugs to the extracellular compartment, leading to the ineffectiveness of chemotherapy. ${ }^{56}$ The concept of utilization of hyperthermia on overcoming MDR has been well demonstrated previously. Several earlier works showed that heat treatment could suppress P-glycoproteinmediated drug efflux on cancer cell lines. ${ }^{57,58}$ Meanwhile, the detailed mechanism was not well understood. In recent years, the mechanism was further examined by elucidating the effects of hyperthermia on the inactivation of P-gp. ${ }^{59}$ It was reported that heat generation inside the cells could potentially damage mitochondria, resulting in the shortage of ATP, a crucial energy molecule required for the activation of P-gp. Since heat-mediated inactivation on P-gp should be independent of the sources/materials of heat generation, we anticipated that the proposed HADP platform acts in a similar mechanism on overcoming MDR. To examine the potentials of utilizing HADP on treating MDR cancers, a multidrug-resistant human breast cancer cell line (MCF7/ ADR) and its normal counterpart (MCF7) were used as the in vitro study model. As expected, MCF7/ADR, compared to MCF7, displayed a typical survival resistance to free DOX (Figure 6B and C). Without laser irradiation, high cell viability $(>80 \%)$ was observed from MCF7 or MCF7/ADR treated with the NP groups (HDP, HAP, or HADP). A laser irradiation dose-dependent decrease in cell viability was confirmed from cells that received HAP or HADP treatments. Among them, greater cell viability decrease was achieved by HADP, possibly due to the additional cytotoxic effects from hyperthermia-mediated DOX release. Highest anti-cancer cell effects were demonstrated from treating MCF7 or MCF/ ADR cells with the HADP, followed by $808 \mathrm{~nm}$ laser irradiation. It means that the combination of photothermal therapy and chemotherapy could be achieved of the proposed HADP. Next, the in vivo therapeutic effects of utilizing HADP for combined photothermal therapy and chemo therapy were investigated on the murine colon cancer (CT26) model. 

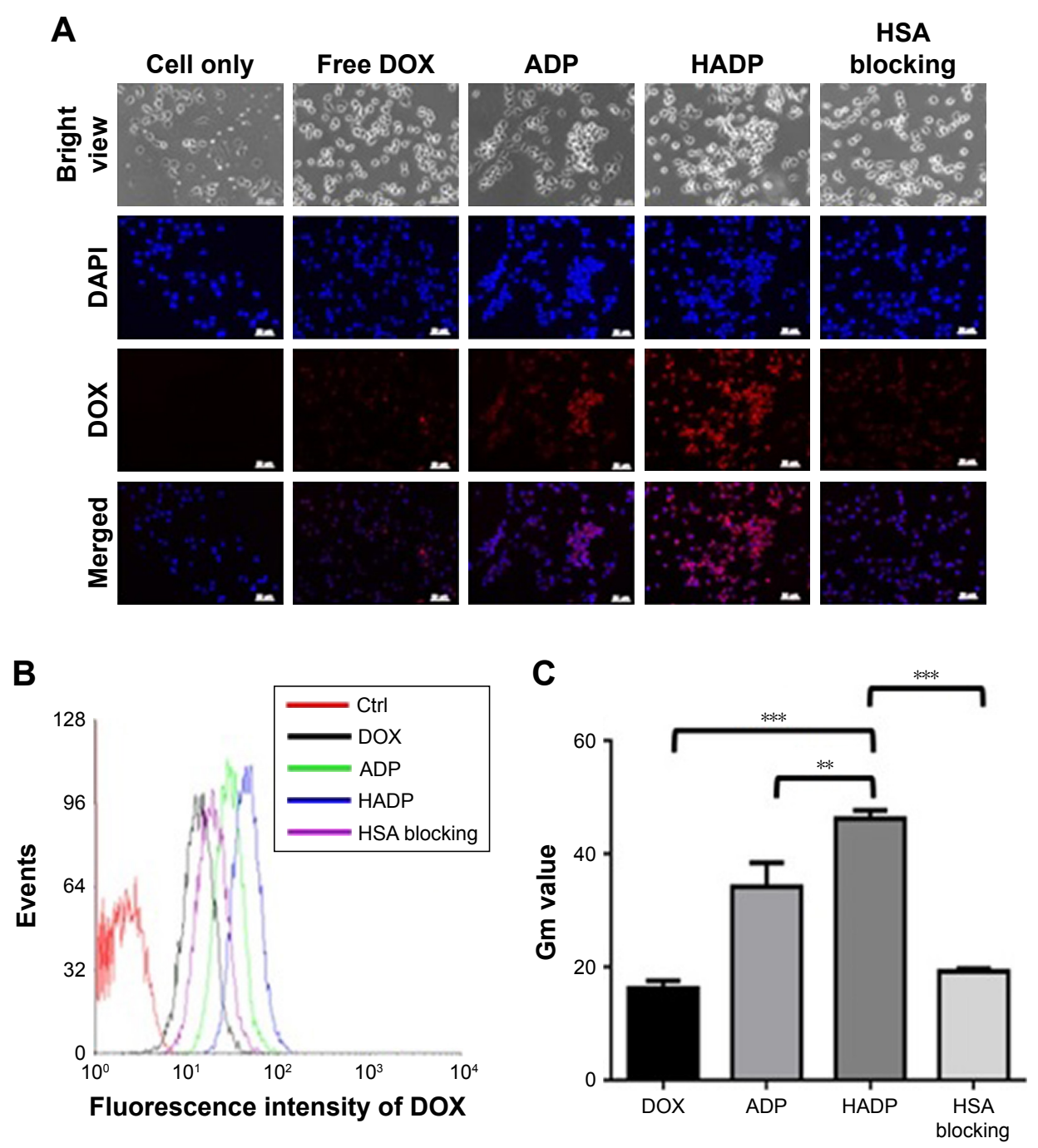

Figure 5 Cellular uptake of drug-loaded NPs on CT26 cell line.

Notes: (A) Fluorescence images of CT26 cells incubated with free DOX, ADP NPs, HADP NPs, and HSA blocking. Red: DOX fluorescence; Blue: cell nuclei (scale bars are $50 \mu \mathrm{m})$. Flow cytometry analysis is shown by histogram (B) and quantified by geometric means value $(\mathbf{C})$. $* * P<0.01$ and $* * * P<0.001$.

Abbreviations: ADP, AuNR/DOX/PLGA; AuNR, gold nanorod; Ctrl, control; DOX, doxorubicin; HADP, HSA/AuNR/DOX-PLGA; HSA, human serum albumin; NP, nanoparticle; PLGA, poly(lactic-co-glycolic acid).

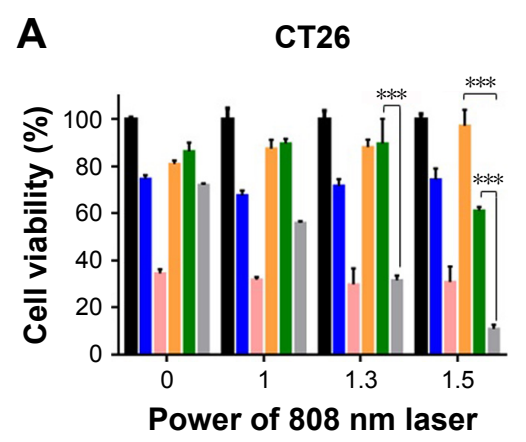

$\left(\mathrm{W} / \mathrm{cm}^{2}\right)$
B

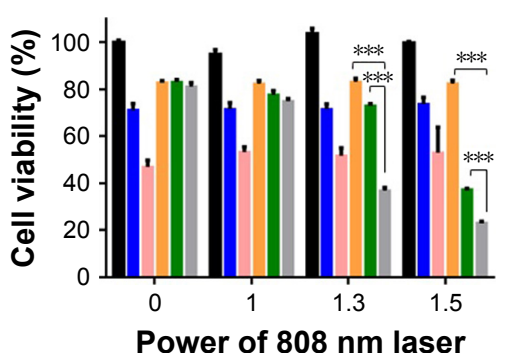

$\left(\mathbf{W} / \mathrm{cm}^{2}\right)$
C

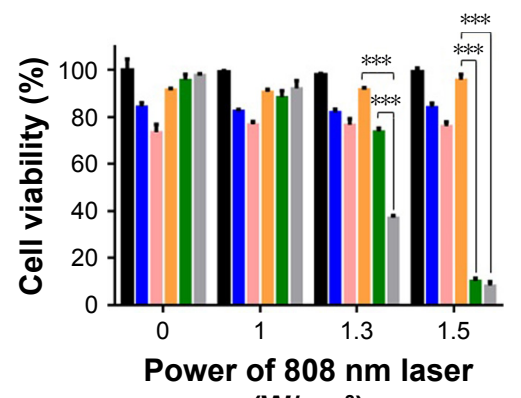

$\left(\mathrm{W} / \mathrm{cm}^{2}\right)$

Cell only DOX $10 \mu \mathrm{M} \quad$ DOX $15 \mu \mathrm{M} \quad$ HSA-DOX/PLGA $\quad$ HSA-AuNR/PLGA HSA-AuNR/DOX/PLGA

Figure 6 In vitro assessments of combined photothermal- and chemo-based anticancer effects of the designated NPs.

Notes: Various cell lines were investigated in this study, including (A) CT26, (B) MCF7, and (C) MCF7/ADR. The cells were incubated with free DOX, HDP NPs (chemotherapy), HAP NPs (photothermal therapy), or HSA-ADP NPs (combine therapy), followed by laser irradiation for different periods of time. Data represent the mean $\pm S E ; n=3$. $* * * P<0.001$. Abbreviations: ADP, AuNR/DOX/PLGA; AuNR, gold nanorod; DOX, doxorubicin; HAP, HSA-AuNR/PLGA; HDP, HSA-DOX/PLGA; HSA, human serum albumin; NP, nanoparticle; PLGA, poly(lactic-co-glycolic acid); SE, standard error. 
A

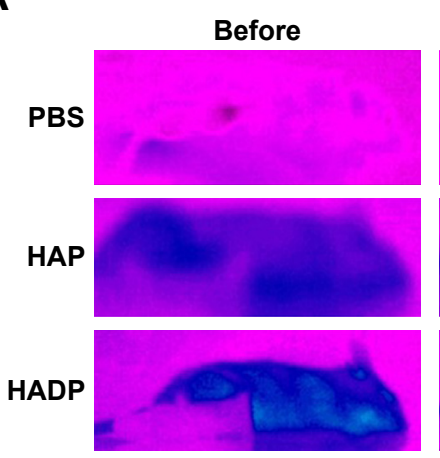

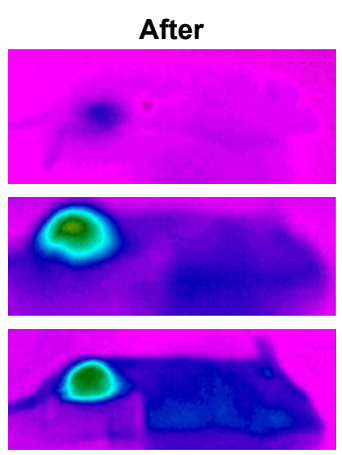

B

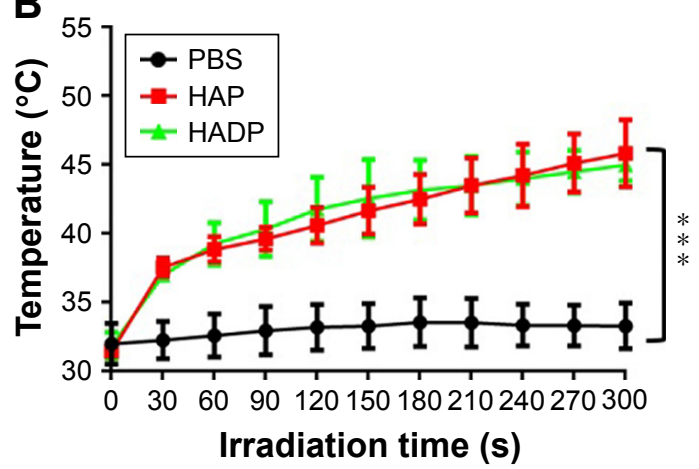

Figure 7 In vivo photothermal effect.

Notes: (A) CT26 tumor-bearing mice was injected intravenously with PBS, HAP, or HADP. Twenty-four hours after injection, the tumors were irradiated with NIR laser $\left(808 \mathrm{~nm}, \mathrm{I} .0 \mathrm{~W} / \mathrm{cm}^{2}\right)$ for 5 minutes, and heat images were taken using a thermal camera. (B) Quantitative representation of temperature changes during the period of NIR laser exposure. $* * * P<0.001$.

Abbreviations: AuNR, gold nanorod; DOX, doxorubicin; HADP, HSA/AuNR/DOX-PLGA; HAP, HSA-AuNR/PLGA; HDP, HSA-DOX/PLGA; HSA, human serum albumin; NIR, near infrared; PLGA, poly(lactic-co-glycolic acid).

\section{Therapeutic effects of HADP on the animal cancer model}

Photothermal effect of the HADP was examined on CT26 tumor-bearing mice. Twenty-four hours after i.v. injection of PBS, HAP, or HADP, the tumors were irradiated with $808 \mathrm{~nm}$ NIR laser for 5 minutes. Figure 7 shows that no noticeable temperature rise was observed from the PBS control group; on the contrary, significant temperature increase was shown from the AuNR-containing groups (HAP or HADP). The results indicate that the systematically injected HAP or HADP could circulate and accumulate in tumors to exert photothermal effect upon receiving NIR irradiation. It is also noted that the temperature $\left(45^{\circ} \mathrm{C}\right)$ of tumor surface after NIR irradiation was still lower than the glass transition temperature $\left(48^{\circ} \mathrm{C}-52^{\circ} \mathrm{C}\right)$ of PLGA used in this study. This discrepancy might be due to the heat dissipation during the transmission process within the tumors. When receiving NIR irradiation, heat generated from the AuNR transmits to its surroundings (from proximal to distal site), including PLGA shell, cytoplasm, extracellular matrix, and tumor surface. Thus, we speculate that, comparing to the tumor surface, higher temperature in the PLGA shell could trigger drug release. To further clarify this possibility, direct observation of NIR irradiation-mediated drug release from the HADP within tumor will be required in the future. We further examined the combined photothermal and chemotherapeutic effects of HADP on the CT26 colon cancer model. The sizes of CT26 tumors were compared on mice that received various treatments, including PBS, free DOX, HDP NPs (chemotherapy effect), HAP+laser (photothermal therapy effect), and HADP
A Tumor inhibition

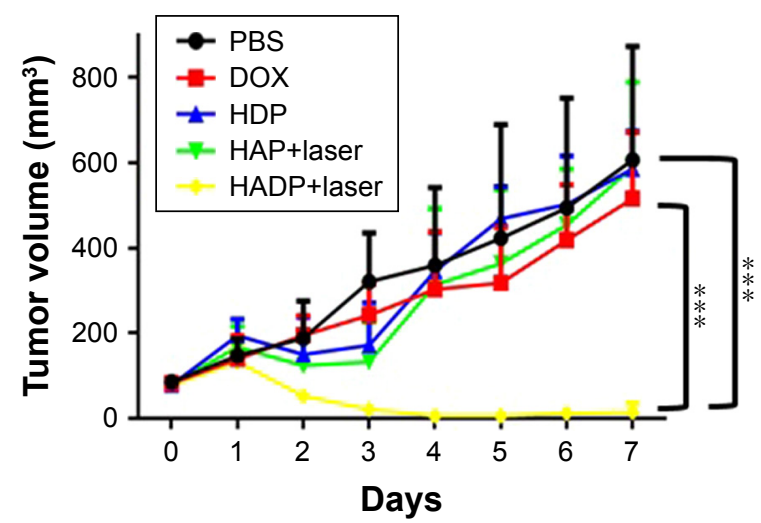

B

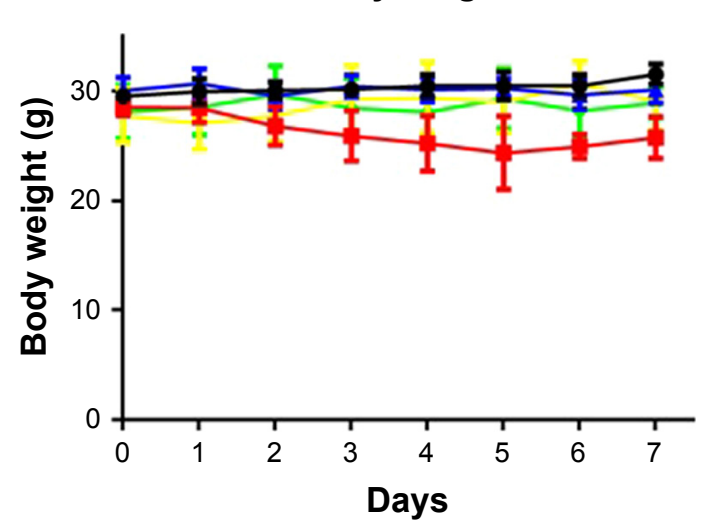

Figure 8 In vivo tumor inhibition of the HADP.

Notes: (A) Time course study of tumor volume changes. (B) Time course study of mouse body weight. Data represent the mean \pm SE; $n=4-5$. $* * * P<0.00$ I.

Abbreviations: AuNR, gold nanorod; DOX, doxorubicin; HADP, HSA/AuNR/DOX-PLGA; HAP, HSA-AuNR/PLGA; HSA, human serum albumin; PLGA, poly(lactic-co-glycolic acid); SE, standard error. 

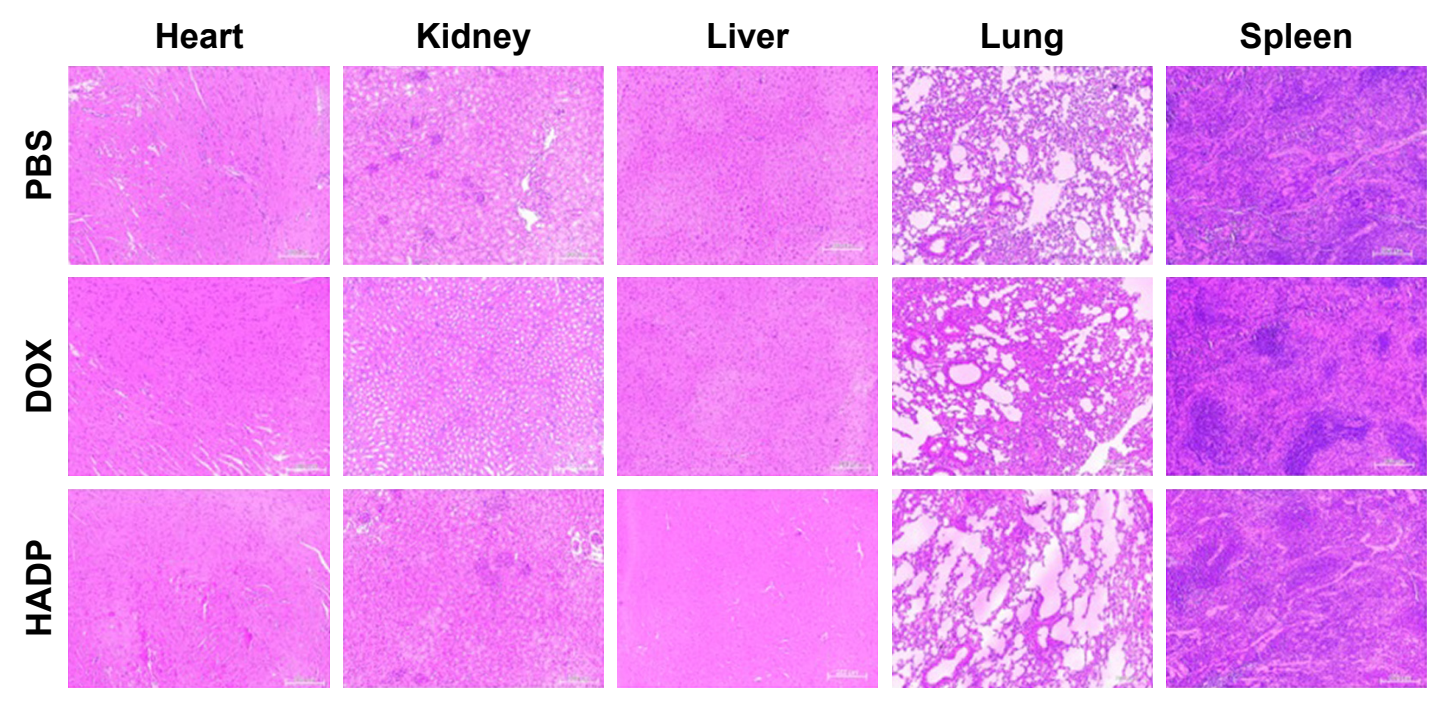

Figure 9 Histological analysis of organs excised from mice that received PBS, DOX, or the HADP injections.

Abbreviations: AuNR, gold nanorod; DOX, doxorubicin; HADP, HSA/AuNR/DOX-PLGA; HSA, human serum albumin; PLGA, poly(lactic-co-glycolic acid).

NPs+laser (combination of chemotherapy and photothermal therapy effect). After drug injections for 24 and 48 hours, mice tumors were irradiated by NIR laser for 5 minutes. The results (Figure 8A) show that the mice that received HADP+laser treatment displayed the best tumor suppression effects compared to the PBS (40.52-fold), free DOX, HDP, or photothermal therapy-treated groups. It was also noticed that all the PLGA NP groups (HAP, HDP, or HADP) did not cause any significant change in body weight of mice in contrast to the gradual decrease in body weight (Figure 8B) on free DOX-treated mice. Biocompatibility of the HADP was evaluated by histological examining (Figure 9) of the major organs (heart, kidney, liver, lung, and spleen) from treated mice. No noticeable tissue damage or infiltration of inflammatory cells was observed from any of these major organs.

\section{Conclusion}

We have successfully prepared an NIR-triggered drug release system by encapsulating hydrophobic AuNR and DOX inside the PLGA NPs. The NPs were further modified with HSA on the surface via electrostatic interactions that exhibited excellent colloidal stability in serum protein-containing environment. By using this NP system, significant anticancer effects on human breast cancer cells or murine colon cancer cells were demonstrated. The HADP NPs show promising combined photothermal and chemotherapeutic effect on a murine colon cancer animal model without inducing undesired side effects. Based on these features, we believe that the proposed nanoparticulate system is worth of further development into a promising drug delivery carrier for treating malignant cancers.

\section{Acknowledgment}

This research was financially supported by Ministry of Science and Technology of Taiwan (MOST 106-2119 M-007-017) and National Tsing Hua University (106J00X 9K6/106N522CE1).

\section{Disclosure}

The authors report no conflicts of interest in this work.

\section{References}

1. Park H, Yang J, Lee J, Haam S, Choi IH, Yoo KH. Multifunctional nanoparticles for combined doxorubicin and photothermal treatments. ACS Nano. 2009;3(10):2919-2926.

2. Misra R, Sahoo SK. Intracellular trafficking of nuclear localization signal conjugated nanoparticles for cancer therapy. Eur J Pharm Sci. 2010;39(1-3):152-163.

3. Wang H, Zhao Y, Wu Y, et al. Enhanced anti-tumor efficacy by codelivery of doxorubicin and paclitaxel with amphiphilic methoxy PEGPLGA copolymer nanoparticles. Biomaterials. 2011;32(32):8281-8290.

4. Depan D, Shah J, Misra RDK. Controlled release of drug from folatedecorated and graphene mediated drug delivery system: Synthesis, loading efficiency, and drug release response. Materials Science and Engineering: C. 2011;31(7):1305-1312.

5. Kost J, Langer R. Responsive polymeric delivery systems. Adv Drug Deliv Rev. 2001;46(1-3):125-148.

6. Kumar CS, Mohammad F. Magnetic nanomaterials for hyperthermiabased therapy and controlled drug delivery. Adv Drug Deliv Rev. 2011; 63(9):789-808.

7. Popat A, Liu J, Lu Gao Qing (max), Qiao SZ. A pH-responsive drug delivery system based on chitosan coated mesoporous silica nanoparticles. J Mater Chem. 2012;22(22):11173-11178.

8. Rösler A, Vandermeulen GW, Klok HA. Advanced drug delivery devices via self-assembly of amphiphilic block copolymers. Adv Drug Deliv Rev. 2001;53(1):95-108.

9. Yang P, Gai S, Lin J. Functionalized mesoporous silica materials for controlled drug delivery. Chem Soc Rev. 2012;41(9):3679-3698.

10. Yang X, Liu X, Liu Z, Pu F, Ren J, Qu X. Near-infrared light-triggered, targeted drug delivery to cancer cells by aptamer gated nanovehicles. Adv Mater. 2012;24(21):2890-2895. 
11. Zhang Q, Ko NR, Oh JK. Recent advances in stimuli-responsive degradable block copolymer micelles: synthesis and controlled drug delivery applications. Chem Commun (Camb). 2012;48(61):7542-7552.

12. Lai PY, Huang RY, Lin SY, Lin YH, Chang CW. Biomimetic stem cell membrane-camouflaged iron oxide nanoparticles for theranostic applications. RSC Adv. 2015;5(119):98222-98230.

13. Hsieh CC, Kang ST, Lin YH, et al. Biomimetic Acoustically-Responsive Vesicles for Theranostic Applications. Theranostics. 2015;5(11): 1264-1274.

14. Wang J, Wang F, Li F, et al. A multifunctional poly(curcumin) nanomedicine for dual-modal targeted delivery, intracellular responsive release, dual-drug treatment and imaging of multidrug resistant cancer cells. J Mater Chem B. 2016;4(17):2954-2962.

15. Chang YT, Liao PY, Sheu HS, Tseng YJ, Cheng FY, Yeh CS. Nearinfrared light-responsive intracellular drug and siRNA release using au nanoensembles with oligonucleotide-capped silica shell. Adv Mater. 2012;24(25):3309-3314.

16. Chen R, Zheng X, Qian H, Wang X, Wang J, Jiang X. Combined near-IR photothermal therapy and chemotherapy using gold-nanorod/chitosan hybrid nanospheres to enhance the antitumor effect. Biomater Sci. 2013;1(3):285-293.

17. You J, Zhang G, Li C. Exceptionally high payload of doxorubicin in hollow gold nanospheres for near-infrared light-triggered drug release. ACS Nano. 2010;4(2):1033-1041.

18. Lee SM, Park H, Choi JW, Park YN, Yun CO, Yoo KH. Multifunctional nanoparticles for targeted chemophotothermal treatment of cancer cells. Angew Chem Int Ed Engl. 2011;50(33):7581-7586.

19. Yang J, Lee J, Kang J, et al. Smart drug-loaded polymer gold nanoshells for systemic and localized therapy of human epithelial cancer. $A d v$ Mater. 2009;21(43):4339-4342.

20. Zhang W, Wang F, Wang Y, et al. pH and near-infrared light dualstimuli responsive drug delivery using DNA-conjugated gold nanorods for effective treatment of multidrug resistant cancer cells. $J$ Control Release. 2016;232:9-19.

21. Weissleder R. A clearer vision for in vivo imaging. Nat Biotechnol. 2001;19(4):316-317.

22. Hribar KC, Lee MH, Lee D, Burdick JA. Enhanced release of small molecules from near-infrared light responsive polymer-nanorod composites. ACS Nano. 2011;5(4):2948-2956.

23. Lee SM, Kim HJ, Kim SY, et al. Drug-loaded gold plasmonic nanoparticles for treatment of multidrug resistance in cancer. Biomaterials. 2014;35(7):2272-2282.

24. Lee SM, Park H, Yoo KH. Synergistic cancer therapeutic effects of locally delivered drug and heat using multifunctional nanoparticles. Adv Mater. 2010;22(36):4049-4053.

25. Yan B, Boyer JC, Branda NR, Zhao Y. Near-infrared light-triggered dissociation of block copolymer micelles using upconverting nanoparticles. J Am Chem Soc. 2011;133(49):19714-19717.

26. You J, Shao R, Wei X, Gupta S, Li C. Near-infrared light triggers release of Paclitaxel from biodegradable microspheres: photothermal effect and enhanced antitumor activity. Small. 2010;6(9):1022-1031.

27. Kong G, Braun RD, Dewhirst MW. Characterization of the effect of hyperthermia on nanoparticle extravasation from tumor vasculature. Cancer Res. 2001;61(7):3027-3032.

28. Zhong Y, Wang C, Cheng L, Meng F, Zhong Z, Liu Z. Gold nanorod-cored biodegradable micelles as a robust and remotely controllable doxorubicin release system for potent inhibition of drugsensitive and -resistant cancer cells. Biomacromolecules. 2013;14(7): 2411-2419.

29. Zhang W, Guo Z, Huang D, Liu Z, Guo X, Zhong H. Synergistic effect of chemo-photothermal therapy using PEGylated graphene oxide. Biomaterials. 2011;32(33):8555-8561.

30. Yu HJ, Cui ZR, Yu PC, et al. pH- and NIR Light-Responsive Micelles with Hyperthermia-Triggered Tumor Penetration and Cytoplasm Drug Release to Reverse Doxorubicin Resistance in Breast Cancer. Adv Funct Mater. 2015;25(17):2489-2500.
31. Huang X, El-Sayed MA. Gold nanoparticles: Optical properties and implementations in cancer diagnosis and photothermal therapy. $J A d v$ Res. 2010;1(1):13-28.

32. Xiao Y, Hong H, Matson VZ, et al. Gold Nanorods Conjugated with Doxorubicin and cRGD for Combined Anticancer Drug Delivery and PET Imaging. Theranostics. 2012;2(8):757-768.

33. Venkatesan R, Pichaimani A, Hari K, Balasubramanian PK, Kulandaivel J, Premkumar K. Doxorubicin conjugated gold nanorods: a sustained drug delivery carrier for improved anticancer therapy. J Mater Chem B. 2013;1(7):1010-1018.

34. Elzoghby AO, Samy WM, Elgindy NA. Albumin-based nanoparticles as potential controlled release drug delivery systems. J Control Release. 2012;157(2):168-182.

35. Kratz F. Albumin as a drug carrier: design of prodrugs, drug conjugates and nanoparticles. J Control Release. 2008;132(3):171-183.

36. Wang W, Huang Y, Zhao S, Shao T, Cheng Y. Human serum albumin (HSA) nanoparticles stabilized with intermolecular disulfide bonds. Chem Commun (Camb). 2013;49(22):2234-2236.

37. Kratz F, Elsadek B. Clinical impact of serum proteins on drug delivery. J Control Release. 2012;161(2):429-445.

38. Lin SY, Huang RY, Liao WC, Chuang CC, Chang CW. Multifunctional PEGylated Albumin/IR780/Iron Oxide Nanocomplexes for Cancer Photothermal Therapy and MR Imaging. Nanotheranostics. 2018;2(2): 106-116.

39. Ding D, Tang X, Cao X, et al. Novel self-assembly endows human serum albumin nanoparticles with an enhanced antitumor efficacy. AAPS PharmSciTech. 2014;15(1):213-222.

40. Elsadek B, Kratz F. Impact of albumin on drug delivery - new applications on the horizon. J Control Release. 2012;157(1):4-28.

41. Frei E. Albumin binding ligands and albumin conjugate uptake by cancer cells. Diabetol Metab Syndr. 2011;3(1):11.

42. Kim TH, Jiang HH, Youn YS, et al. Preparation and characterization of water-soluble albumin-bound curcumin nanoparticles with improved antitumor activity. Int J Pharm. 2011;403(1-2):285-291.

43. Quan Q, Xie J, Gao H, et al. HSA coated iron oxide nanoparticles as drug delivery vehicles for cancer therapy. Mol Pharm. 2011;8(5): 1669-1676.

44. Sheng Z, Hu D, Zheng M, et al. Smart human serum albuminindocyanine green nanoparticles generated by programmed assembly for dual-modal imaging-guided cancer synergistic phototherapy. ACS Nano. 2014;8(12):12310-12322.

45. Makadia HK, Siegel SJ. Poly lactic-co-glycolic acid (PLGA) as biodegradable controlled drug delivery carrier. Polymers (Basel). 2011; 3(3):1377-1397.

46. Alkilany AM, Thompson LB, Boulos SP, Sisco PN, Murphy CJ. Gold nanorods: their potential for photothermal therapeutics and drug delivery, tempered by the complexity of their biological interactions. Adv Drug Deliv Rev. 2012;64(2):190-199.

47. Gole A, Orendorff CJ, Murphy CJ. Immobilization of gold nanorods onto acid-terminated self-assembled monolayers via electrostatic interactions. Langmuir. 2004;20(17):7117-7122.

48. von Maltzahn G, Park JH, Agrawal A, et al. Computationally guided photothermal tumor therapy using long-circulating gold nanorod antennas. Cancer Res. 2009;69(9):3892-3900.

49. Wilson K, Homan K, Emelianov S. Biomedical photoacoustics beyond thermal expansion using triggered nanodroplet vaporization for contrastenhanced imaging. Nat Commun. 2012;3:618.

50. Lamprecht A, Ubrich N, Hombreiro Pérez M, Lehr C, Hoffman M, Maincent $P$. Influences of process parameters on nanoparticle preparation performed by a double emulsion pressure homogenization technique. Int J Pharm. 2000;196(2):177-182.

51. Manchanda R, Fernandez-Fernandez A, Nagesetti A, Mcgoron AJ. Preparation and characterization of a polymeric (PLGA) nanoparticulate drug delivery system with simultaneous incorporation of chemotherapeutic and thermo-optical agents. Colloids Surf B Biointerfaces. 2010;75(1):260-267. 
52. Song X, Zhao Y, Hou S, et al. Dual agents loaded PLGA nanoparticles: systematic study of particle size and drug entrapment efficiency. Eur J Pharm Biopharm. 2008;69(2):445-453.

53. Chuang CC, Chang CW. Complexation of bioreducible cationic polymers with gold nanoparticles for improving stability in serum and application on nonviral gene delivery. ACS Appl Mater Interfaces. 2015;7(14):7724-7731.

54. Sau TK, Murphy CJ. Seeded high yield synthesis of short Au nanorods in aqueous solution. Langmuir. 2004;20(15):6414-6420.

55. Huang RY, Chiang PH, Hsiao WC, Chuang CC, Chang CW. Redox-Sensitive Polymer/SPIO Nanocomplexes for Efficient Magnetofection and MR Imaging of Human Cancer Cells. Langmuir. 2015;31(23):6523-6531.
56. Shen F, Chu S, Bence AK, et al. Quantitation of doxorubicin uptake, efflux, and modulation of multidrug resistance (MDR) in MDR human cancer cells. J Pharmacol Exp Ther. 2008;324(1):95-102.

57. Liu Y, Cho CW, Yan X, et al. Ultrasound-Induced hyperthermia increases cellular uptake and cytotoxicity of P-glycoprotein substrates in multi-drug resistant cells. Pharm Res. 2001;18(9): 1255-1261.

58. Liu Y, Lillehei K, Cobb WN, Christians U, Ng KY. Overcoming MDR by ultrasound-induced hyperthermia and P-glycoprotein modulation. Biochem Biophys Res Commun. 2001;289(1):62-68.

59. Tu Z, Qiao H, Yan Y, et al. Directed Graphene-Based Nanoplatforms for Hyperthermia: Overcoming Multiple Drug Resistance. Angew Chem Int Ed Engl. 2018;57(35):11198-11202.
International Journal of Nanomedicine

\section{Publish your work in this journal}

The International Journal of Nanomedicine is an international, peerreviewed journal focusing on the application of nanotechnology in diagnostics, therapeutics, and drug delivery systems throughout the biomedical field. This journal is indexed on PubMed Central, MedLine, CAS, SciSearch $®$, Current Contents $\AA /$ Clinical Medicine,

\section{Dovepress}

Journal Citation Reports/Science Edition, EMBase, Scopus and the Elsevier Bibliographic databases. The manuscript management system is completely online and includes a very quick and fair peer-review system, which is all easy to use. Visit http://www.dovepress.com/ testimonials.php to read real quotes from published authors.

Submit your manuscript here: http://www.dovepress.com/international-journal-of-nanomedicine-journal 